ARTICLE

Grace Anyaegbu

Office for National Statistics

\title{
Using the OECD equivalence scale in taxes and benefits analysis
}

\section{Introduction}

- he McClements equivalence scale has been used by researchers and government departments in the UK to take account of the differing needs and economies of scale of households. This makes larger households better off than single adult households. However, many organisations have shifted toward using the OECD (Organisation for Economic Cooperation and Development) equivalence scale in their analysis. For example, the Statistical Office of the European Union (EUROSTAT) opted for the OECD equivalence scale in their analysis of income using EU Survey of Incomes and Living Conditions data. Furthermore, the Department for Work and Pensions (DWP) began to use the OECD equivalence scale from 2005/06 in their Households Below Average Income (HBAI) publication ${ }^{1}$.

The ETB is a long-standing analysis published every year in Economic \& Labour Market Review (see Barnard 2009). It is based on income and expenditure data from the Living Costs and Food Survey ${ }^{2}$ (LCF), which was previously known as the Expenditure and Food Survey.

The analysis has used the McClements equivalence scales since 1977 giving a long, consistent series but with a lack of comparability between the estimates produced in ETB and other household income statistics. This article seeks to outline the effects of moving the ETB analysis from the McClements scale to the OECD scale and also present the timetable for the move to the OECD scale.
The article shows that:

- Using the OECD equivalence scale, compared with the McClements scale, gives more weight to the first adult in any household than second and subsequent adults. This has the effect of giving single adult households a smaller equivalised income relative to couple households than the McClements scale

- Changing equivalence scales (equivalisation and equivalence are terms that are used interchangeably) makes little difference to the estimated Gini coefficient for disposable income, but has a bigger effect on the Gini coefficients for the original, gross and post-tax income

- The effect of a change in equivalence scales increases income inequality for retired households and reduces inequality for non-retired households, as measured by disposable income

- The OECD equivalence scale cause estimates of disposable income to fall for the lower income decile groups, and to increase for higher income decile groups. This means that the gap between the bottom and top decile will widen slightly using the OECD scale

\section{Effects of taxes and benefits on household income (ETB)} analysis

ETB analysis shows how Government intervention, through the tax and benefit system, affects the income of households. It covers the whole income distribution and includes the effects of indirect taxes, such 
as VAT and duty on alcoholic beverages, as well as estimating the cash value of free or subsidised services (for example, government spending on education and healthcare). It also shows where different types of households are in the income distribution and looks at the changing levels of income inequality over time. ETB results are designed to show the position for a particular year rather than trends in income levels over time, although trends in the distribution of income are given.

\section{Income equivalisation}

The process of income equivalisation involves adjusting a household's income based on its size and composition. The income adjustment is done using an equivalence scale to obtain the equivalised household income for each household. An equivalence scale is the ratio of the amount of income needed by a household to achieve a particular standard of living, given the household composition, to the amount of income needed by a 'reference' household achieving the same standard of living. The household equivalence value is calculated by summing the appropriate equivalence scales for each household member. Equivalised household income is then calculated by dividing total household income by the household equivalence value.

For example, if the reference household is taken as a childless couple and the equivalence scale for a couple with children is estimated at 1.5 , it means that a couple with children need one and a half times as much income as a childless couple to reach a particular standard of living. The simplest method of adjusting for differences in household size is to divide the income of households by the number of people in it, so that household income is presented on a per capita basis. This method assumes that all individuals have the same resource needs if they are to enjoy the same standard of living, and that there are no economies of scale obtained from living together. Therefore, equivalence scales have been devised to take these factors into account. However, it is difficult to define and estimate equivalence scales that take all relevant factors into account and which can be used for different analyses. As a result, analysts tend to use simple equivalence scales which are chosen subjectively but are nevertheless consistent with the quantitative research that has been undertaken.

\section{Equivalence scales}

Different equivalence scales have been developed to make adjustments to

Table 1

\section{Equivalence scales (before housing costs)}

McClements Scale OECD-modified Scale

First adult

Spouse

Other second adult

Third adult

Subsequent adults

$0.61-0.67$

0.39

0.46

0.42

0.36

0.33

0.33

0.33

Each dependent aged:

0 to 1

2 to 4

0.09

0.18

0.18
0.21

5 to 7

8 to 10

11 to 12

13

14

15

16 or over

0.23

0.25

0.27

0.27

0.27

0.36

the actual incomes of households and these scales differ in their detail and methodology. In many scales, the household size is the only factor used in calculating the equivalence value, while in those scales with other factors like differences in geographic areas, expenditure patterns and transport costs, the size of the household has the greatest weight (see Chanfreau and Buchardt 2008 and OECD 2009 for more information on equivalence scales).

Some of the most commonly used equivalence scales include: The OECD 'Oxford' scales, the OECD-modified scale (referred to as the OECD scales for simplicity), the McClements scale and the square root scale. The McClements scale was developed in the mid-1970s specifically for use in the UK to take account of the effects of the number of children, and ages of children, on the living standards of the household. The McClements scale assumes the equivalised income of a cohabiting couple living on their own is equal to their actual income. The equivalised income of larger households is less than their actual household income, and the equivalised income of a single-person household is greater than the person's actual income. The scale takes into account both the greater income needs of larger families and economies of scale achieved when people live together. Economies of scale arise when households with multiple members share resources like water and electricity, making larger households better off due to lower per person costs.

The OECD scale, on the other hand, was proposed by Hagenaars, De Vos and Zaidi in 1994, for use across the world. This scale assigns a weight of 1.0 for the first adult in a household, 0.5 for each additional adult and a weight of 0.3 for each child (aged
0-14 years). It differs from the McClements scale, which assigns specific weights based on the type of household members and the ages of the child. In this analysis, the OECD scale has been rescaled so that the couple household equivalence value is 1.0 , to make it easier to compare with the McClements scale. The OECD scale assumes that single adults need a higher proportion of a couple's income to maintain the same standard of living. Households with spouses and additional adults need the addition of a lower proportion of a couple's income to maintain the same standard of living. The scale also assumes that households with children aged 0 to 4 years and young teenagers aged 14 and 15 years need the addition of a higher proportion of a couple's income to main the same standard of living. Households with children aged 5 to 13 years and teenagers aged 16 years and over need the addition of a lower proportion of a couple's income to maintain the same standard of living. The McClements and re-scaled OECD equivalence scales are presented in Table 1.

\section{Effects of using OECD equivalence scales in ETB analysis}

The ETB analysis presents households' original income, gross income, disposable income, post-tax income and final income. Original income is income received from employment, occupational pensions, investments and other non-government sources. Gross income is calculated by adding cash benefits (for example, state pensions and widow's benefits) to original income. Subtracting direct taxes from gross income gives the household's disposable income. Households pay indirect taxes like VAT and other duties from the purchase of 
Table 2

Households in each income quintile group by household type

\begin{tabular}{|c|c|c|c|c|c|c|}
\hline \multirow[b]{3}{*}{ Household type } & \multicolumn{6}{|c|}{ Percentages } \\
\hline & \multicolumn{5}{|c|}{ Quintile groups of ALL households' } & All \\
\hline & Bottom & 2nd & $3 r d$ & 4th & Top & holds \\
\hline
\end{tabular}

\section{Retired}

\section{1 adult}

McClements scale

OECD-modified scale

Difference

$\begin{array}{rr}20 & 22 \\ 23 & 24 \\ 3 & 2\end{array}$

22

2 or more adults

McClements scale

OECD-modified scale

Difference

19

17

$-2$

Non-retired

1 adult

McClements scale

OECD-modified scale

Difference

1 adult with children

McClements scale

OECD-modified scale

Difference

2 adults

McClements scale

OECD-modified scale

Difference

2 adults with 1 child

McClements scale

OECD-modified scale

Difference

2 adults with 2 children

McClements scale

OECD-modified scale

Difference

2 adults with 3 or more children

McClements scale

OECD-modified scale

Difference

3 or more adults

McClements scale

OECD-modified scale

Difference

3 or more adults with children

McClements scale

OECD-modified scale

Difference

16
17
1

9
10
1

10
11
1

\section{4}

13

21

18

1

$$
-1
$$

$-3$

14

14

12

13

1

8

7

$-1$

5
5
0

3
2
-1

1
1

1

$11 \quad 14$

10

$-1$

14
0

19
18
-1

29

43

44

$-1$

30

1

1

$\begin{array}{ll}6 & 8 \\ 5 & 9\end{array}$

5

$-1$

1

9
9

0

8

8

0

8

8

0

10
10
0

\section{0}

$$
11
$$

9

0

$\begin{array}{lllll}4 & 3 & 2 & 2 & 3 \\ 4 & 3 & 2 & 2 & 3 \\ 0 & 0 & 0 & 0 & 0\end{array}$

\section{Note:}

1 All households are ranked by disposable income.

goods and services. These indirect taxes are subtracted from disposable income to give an estimate of post-tax income. Households are also assigned nominal incomes to reflect the receipt of non-cash benefits provided by the state, which are based on the cost of providing the services. These non-cash benefits include Government spending on healthcare and concessionary transport fares. These are added to post-tax income to give a measure of final income.

The income distribution in the ETB analysis is based on a ranking of households by equivalised disposable income into five or ten equally sized groups, that is, quintile or decile groups. The bottom quintile or decile group has the lowest equivalised disposable incomes, while the top quintile or decile group has the highest. Therefore any differences in equivalised disposable income, caused by changing the equivalence scale, will have an effect on the ranking of households and subsequently on the composition of the decile and quintile groups used in presenting data in the ETB analysis. Table 2 compares the percentage of households in each income quintile group by household type and composition using both scales.

Table 2 shows that the bottom quintile group had a greater percentage of one-adult retired households using the OECD scale than those that used the McClements scale. However, the lower quintile groups had similar percentages of two or more adult retired households across scales, though the bottom quintile group calculated using the McClements based estimates had more households for this household type. The lower income quintile groups also had greater percentages of one-adult nonretired households and three or more adult households using the OECD compared with those using the McClements scale. In addition, the bottom quintile calculated using the OECD scale had a greater percentage of one-adult with children (lone parent) households than those that used the McClements scale. This is because the OECD scale has a greater equivalence value for the first adult than the McClements' and also assigns higher equivalence values to children aged $0-4$ years. Thus, the overall equivalence value for lone parent households using the OECD scale is greater than the equivalence value for the same households using the McClements scale. The percentage of two adult households with two children was similar across the two scales.

ETB analysis also calculates Gini coefficients to measure inequality for each measure of income. The Gini coefficient is the most widely used summary measure of the degree of inequality in an income distribution. It takes values from 0 to 100 per cent, where a value of zero would indicate that each household had an equal share of income, while higher values indicate greater inequality. As shown in Table 3, the Gini coefficients for equivalised original and post-tax income reduced slightly using the OECD scale, while Gini coefficients for gross income increased slightly, compared with the McClements scale. However, the most commonly reported measure, the Gini coefficient for household disposable income, remained unchanged. 
Table 3

Gini coefficients for ALL households, 2007/08

\begin{tabular}{lrrrr}
\hline & \multicolumn{4}{c}{ Gini coefficients for ALL households } \\
\cline { 2 - 5 } Equivalisation Scale & Original income & Gross income & Disposable income & Post-tax income \\
\hline McClements Scale & 51.7 & 37.5 & 34.2 & 38.1 \\
OECD-modified Scale & 51.6 & 37.7 & 34.2 & 38.0 \\
Difference & -0.1 & 0.2 & 0.0 & -0.1 \\
\hline
\end{tabular}

Source: Office for National Statistics

Table 4

Gini coefficients for NON-RETIRED households, 2007/08

\begin{tabular}{lcrrr}
\hline & \multicolumn{4}{c}{ Gini coefficients for NON-RETIRED households } \\
\cline { 2 - 5 } Equivalisation Scale & Original income & Gross income & Disposable income & Post-tax income \\
\hline McClements Scale & 44.1 & 36.8 & 34.2 & 38.1 \\
OECD-modified Scale & 43.8 & 36.6 & 33.8 & 37.7 \\
Difference & -0.4 & -0.2 & -0.3 & -0.4 \\
\hline
\end{tabular}

Source: Office for National Statistics

Table 5

Gini coefficients for RETIRED households, 2007/08

\begin{tabular}{lrrrr}
\hline & \multicolumn{4}{c}{ Gini coefficients for RETIRED households } \\
\cline { 2 - 5 } Equivalisation Scale & Original income & Gross income & Disposable income & Post-tax income \\
\hline McClements Scale & 63.8 & 29.2 & 26.9 & 31.2 \\
OECD-modified Scale & 64.0 & 29.4 & 27.0 & 31.1 \\
Difference & 0.2 & 0.2 & 0.1 & -0.1 \\
\hline
\end{tabular}

Source: Office for National Statistics

Table 6

P90/P10 ratio for ALL households, 2007/08

\begin{tabular}{lcrr}
\hline & \multicolumn{3}{c}{ P90/P10 ratio for ALL households } \\
\cline { 2 - 4 } Equivalisation Scale & Gross income & Disposable income & Post-tax income \\
\hline McClements Scale & 5.5 & 4.4 & 5.5 \\
OECD-modified Scale & 5.6 & 4.6 & 5.6 \\
Difference & 0.2 & 0.2 & 0.1 \\
\hline
\end{tabular}

Source: Office for National Statistics

The effect of changing the equivalence scale was larger for non-retired households than for all households. Table 4 shows that the Gini coefficients decreased for all equivalised incomes. This implies that the ETB analysis will report a smaller degree of inequality for non-retired households using the OECD scale than the McClements scale. This may be because the McClements scale gives more weight to the spouse in any household and second and subsequent adults. This has the effect of giving non-retired households a smaller equivalised income under the McClements scale than when using the OECD scales. Thus, the overall equivalence value for non-retired households is greater using the McClements scale than when using the OECD scale.

The Gini coefficient for retired households' equivalised original, gross and disposable incomes increased when the OECD scale was used, although there was a slight reduction in equivalised post-tax income (Table 5). The increase in the Gini coefficients for retired households may be largely because these households are mostly made up of one-adult households (see Table 2). These households would therefore have a larger overall equivalence value for each household when using the OECD scale compared with the McClements scale.

ETB analysis also presents the P90/P10 ratio as an alternative measure of inequality. The P90/P10 ratio is the ratio of the $90^{\text {th }}$ and the $10^{\text {th }}$ percentile in the distribution and shows the distance between the top and bottom of the income distribution. The greater the difference between these two incomes, that is the larger the P90/P10 ratio, the greater the degree of inequality. The P90/P10 ratios calculated for disposable and gross income using the OECD scale was 0.2 percentage points higher than those created using the McClements scale (see

Table 6). This means that the OECD scale produces a higher degree of inequality for disposable and gross income, as measured by the $\mathrm{P} 90 / \mathrm{P} 10$ ratio. The $\mathrm{P} 90 / \mathrm{P} 10$ ratios for post-tax income were very similar using the alternative equivalence scales.

Cash benefits assist in providing a reasonable standard of living to households, particularly those that have little or no income. There are two broad types of cash benefit: contributory benefits, which are paid from the National Insurance Fund, to which individuals and their employers make contributions while working; and non-contributory benefits, many of which are means tested. Contributory benefits include the state retirement pension, incapacity benefit, jobseekers allowance, and widows' benefits. Non-contributory benefits include housing benefit, income support, pension credit, child benefit, various disability and carer's benefits and tax credits.

Table 7 gives a summary of the distribution of cash benefits between quintile groups by household type. It shows that the average cash benefits going to the bottom income quintile for both household types is greater using the McClements scale than when using the OECD scale. This is due to a higher number of single pensioners in the bottom quintile, whose unequivalised incomes are increased by more through equivalisation by the McClements scale than by the OECD scale. Average cash benefits were larger for households in the fourth income quintile using the OECD scale compared with the results using McClements scales. Similarly, for nonretired households, cash benefits provided a greater proportion of gross income for households at the lower end of the income distribution when the OECD scale was used.

In ETB analysis, direct taxes consist of income tax, national insurance contributions and local taxes. ETB analysis also includes analysis of the impact of indirect taxes on household income. Indirect taxes are those incurred by 
Table 7

Cash benefits received in each quintile groups by household type, 2007/08

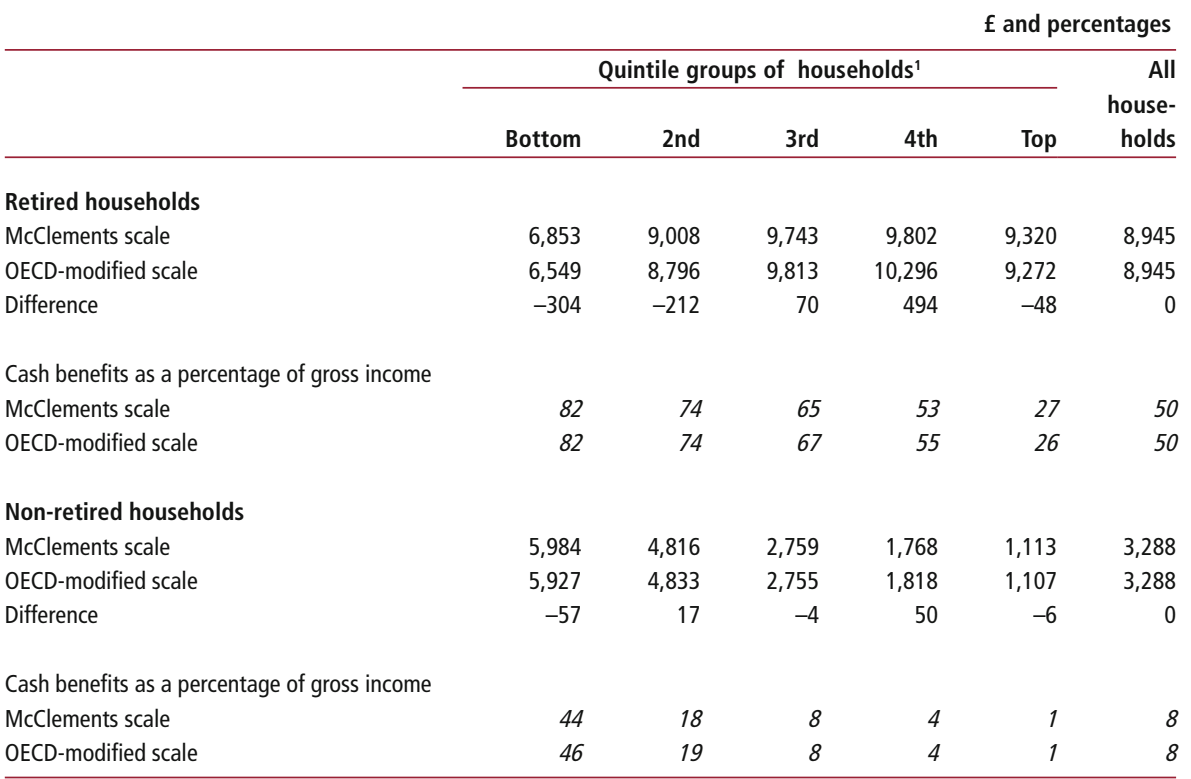

Note:

1 Households are ranked by equivalised disposable income.

Source: Office for National Statistics

\section{Table 8}

Taxes as a percentage of gross income for ALL households by quintile groups, 2007/08

\begin{tabular}{|c|c|c|c|c|c|c|}
\hline & & & & & \multicolumn{2}{|c|}{ Percentages } \\
\hline & \multicolumn{5}{|c|}{ Quintile groups of ALL households ${ }^{1}$} & \multirow{2}{*}{$\begin{array}{r}\text { All } \\
\text { house- } \\
\text { holds }\end{array}$} \\
\hline & Bottom & 2nd & 3 rd & 4th & Top & \\
\hline \multicolumn{7}{|l|}{ Direct taxes } \\
\hline McClements scale & 10.7 & 13.9 & 18.3 & 21.3 & 24.1 & 20.5 \\
\hline OECD-modified scale & 10.3 & 13.6 & 18.4 & 21.8 & 24.9 & 21.0 \\
\hline Difference & -0.4 & -0.3 & 0.1 & 0.5 & 0.8 & 0.5 \\
\hline \multicolumn{7}{|l|}{ Indirect taxes } \\
\hline McClements scale & 27.9 & 18.6 & 15.9 & 13.7 & 10.0 & 13.9 \\
\hline OECD-modified scale & 27.8 & 18.8 & 16.1 & 13.8 & 10.1 & 13.9 \\
\hline Difference & -0.1 & 0.2 & 0.2 & 0.1 & 0.1 & 0.0 \\
\hline \multicolumn{7}{|l|}{ All taxes } \\
\hline McClements scale & 38.6 & 32.5 & 34.2 & 35.0 & 34.1 & 34.4 \\
\hline OECD-modified scale & 38.1 & 32.5 & 34.5 & 35.6 & 35.0 & 35.0 \\
\hline Difference & -0.5 & 0.0 & 0.3 & 0.6 & 0.9 & 0.6 \\
\hline
\end{tabular}

Note:

Source: Office for National Statistics

1 Households are ranked by equivalised disposable income.

Figure 1

Disposable income for ALL households ${ }^{1}$ by decile groups, 2007/08

$\mathfrak{f}$ thousands per year

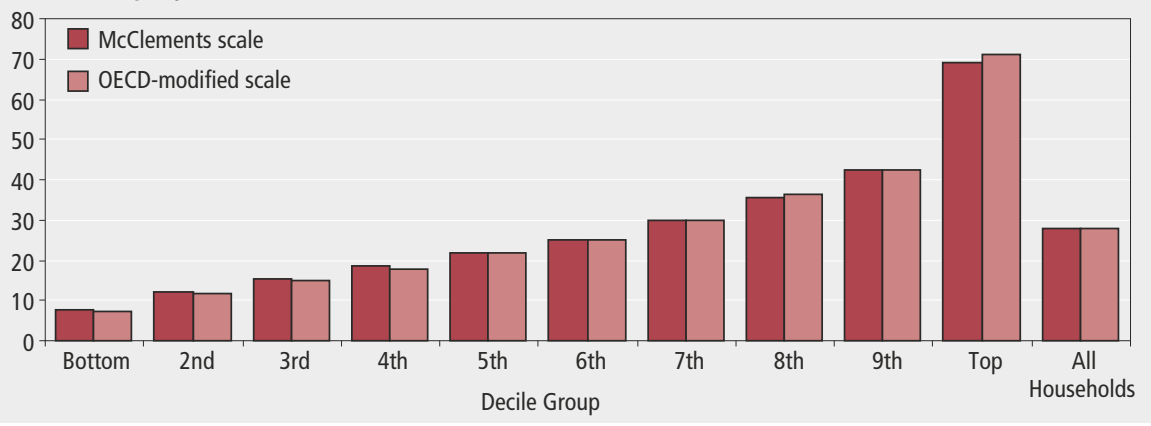

Note:

Source: Office for National Statistics

1 Households are ranked throughout by their grossed equivalised disposable incomes. households when they purchase goods and services. Indirect taxes also include an estimate for payment of intermediate taxes, that is indirect taxes incurred by business which are deemed to be passed onto consumers through the prices that they pay for goods and services. Table 8 presents the effect of changing the equivalence scales on the tax burdens upon each quintile group. In general, the distribution of direct and indirect taxes are very similar using both scales. However, households in the lower end of the income distribution have a higher tax burden when the McClements scale is used compared with the OECD scale. As a result, households at the top of the income distribution were observed to pay more of their income in taxes when the OECD scale was used.

Figure 1 presents the average household annual disposable income for decile groups ranked by equalised disposable income, calculated using both the McClements scale and the OECD scale. This figure is similar for both retired and non-retired households.

Households at the lower end of the income distribution were observed to have slightly higher average disposable household incomes when the McClements scale was used, compared with the OECD scale. Households in the bottom decile in the McClements scale had a disposable income of $£ 7,790$ per year, compared with

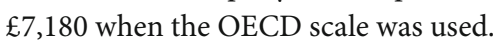
Households in the top three deciles of the income distribution had a slightly higher disposable income when it was calculated using the OECD scale. For instance, households in the top decile had an average disposable income of $£ 71,280$ per year using the OECD scale, compared with $£ 69,210$ using the McClements scale. This means that when the OECD scale is used, households in the top decile were ten times as well-off as households in the bottom decile, while when the McClements scale were used they were only nine times as well-off.

\section{Timetable}

The timetable for the move to the OECD scale has been phased in three parts:

\section{Spring 2010}

The 2008/09 ETB article will be published using the McClements scale. However, Tables 3, 14, 14A, 16 and 18 will be published in the appendix using the OECD scale to enable comparison. Full results using the OECD scale will be available on request. 


\section{Spring 2011}

The 2009/10 ETB article will be published using the OECD scale with tables created with the McClements scale attached as an appendix.

\section{Spring 2012}

The 2010/2011 publication will only publish results using the OECD scale. Results using the McClements scale will be available on request.

\section{Notes}

1. HBAI changed to mainly producing results on the modified OECD scale in the 2005/06 publication, published in 2007. The change to mainly using the OECD scale followed a consultation with key users on which scale the HBAI publication should use.

2. As the LCF is a sample survey, data from it will differ in varying degrees from those of all households in the UK. Using equivalence scales is an arithmetic operation applied to survey data. Estimates after the scale has been applied are therefore still subject to the same degree of sampling variability.

\section{CONTACT}

(실mr@ons.gov.uk

\section{REFERENCES}

Barnard A (2009) 'The effects of taxes and benefits on household income 2007/08',
Economic \& Labour Market Review, Volume 3, No. 8, August, Office of National Statistics. Available at

www.statistics.gov.uk/elmr/08_09/ downloads/ELMR_Aug09_Barnard.pdf

Chanfreau J and Burchardt T (2008)

'Equivalence scales: rationales, uses and assumptions', Scottish Government. Available at www.scotland.gov.uk/Resource/ Doc/933/0079961.pdf

OECD (2009) 'What are equivalence scales?', available at: www.oecd.org/dataoecd/61/52/35411111. pdf 